\title{
Readings of the Post-Crisis Spanish City: Between Social Inequity and Territorial Destruction
}

\author{
Francisco Cebrián-Abellán ${ }^{1}$, María José Piñeira-Mantiñán ${ }^{2}$ and Jesús M. González-Pérez ${ }^{3, *(1)}$ \\ 1 Department of Geography and Land Planning, Faculty of Humanities, Campus Universitario s/n, \\ Benjamín Palencia Building, University of Castilla-La Mancha, 02071 Albacete, Castilla-La Mancha, Spain; \\ Francisco.Cebrian@uclm.es \\ 2 Department of Geography, Faculty of Geography and History, University of Santiago de Compostela, \\ Praza da Universidade, 1, 15782 Santiago de Compostela, A Coruña, Spain; mariajose.pineira@usc.es \\ 3 Department of Geography, Guillem Colom building, University of the Balearic Islands, Cra. de Valldemossa \\ km 7.5, 07122 Palma, Balearic Islands, Spain \\ * Correspondence: jesus.gonzalez@uib.es; Tel.: +34-971-172380
}

Received: 10 April 2019; Accepted: 11 April 2019; Published: 16 April 2019

\begin{abstract}
The 2008 crisis entailed a turning point in the process of creating and managing cities and territories. There has been a change from a city model, based on expansive growth, which was also speculative and deregulated, had provoked an unprecedented expansion of the outskirts of towns and cities, and the artificialization of thousands of hectares of land, to a model based on the reconstruction of the original city, before the impact of the crisis. Gone are the days of urban mega-projects-source of indebtedness for local administrations- and big urbanizations, which, in many occasions, have not been inhabited. The financial, social, and residential reality requires a better thinking of the city models, as well as recuperating the neighborhoods and recomposing the social gap and conflicts, which had become affected by unemployment, evictions, and austerity policies. In this paper, two models of understanding and managing cities have been presented, as a way of identifying strengths, weaknesses, and impacts on the modern city. Several case studies have been collected at a regional level (Extremadura and Valencian Community), and at an urban level (Las Palmas, Madrid, Barcelona, Valencia, and Toledo), and even at a sub-urban level (via the study of certain neighborhoods).
\end{abstract}

Keywords: urbanization process; real estate bubble; urban sprawl; urban vulnerability; residential segregation; urban inequality; Spain

Over the last decades, the dynamics and characters of urbanization in the developed areas have been conditioned by three big change scenarios that were very closely intertwined - in the economy, due to the logics of globalization; in demography, due to the deceleration of dynamics; and in governance, due to the appearance of new actors and local policies [1]. This has not been a homogeneous process, as different contexts, space, and time responses have occurred, which have become accelerated since the end of the last century. All things considered, the biggest impacts and effects were a consequence of the finance capital strategies [2,3], which have influenced the relocation of industrial activities, the progressive switch to a service economy, the appearance of the Information Society, and the effects of modern communication infrastructures. To this, we can add the evolution of behavior, preferences, and the perception of the society regarding environmental and social problems [4,5]. The transformations that have taken place in Spanish cities must be understood in the frame of the aforementioned global rationales. However, these can also be explained by certain distinguishing features, which have given them personality, apart from singular contexts and rhythms, and which have differentiated them in their behavior, in comparison to other neighboring countries. This has meant that there has been a 
change in the systems and urban hierarchies, in city morphology, in the organization processes, and social relations, but it has all occurred with differentiated temporalities and socio-territorial effects.

In terms of time, the urbanization context has been marked by two different periods. The first involved a strong economic and demographic expansion since the end of the twentieth century, until 2008. During this time, the world economy became invigorated, supported by the accelerated transnationalization of capital (in the context of the speculative bubble) [6]. There was free access to cheap credit, favored by bank convenient terms to lend money to governments, companies, and households. People's incomes grew significantly. The capacity of generating incomes and administration investments, increased. This had intense consequences, especially in the real-estate sector, since there was a considerable public and private investment in the elaboration of cities. The most visible result was the creation of new housing, infrastructures, and services, greatly above the real needs of society. In the case of Spain, there were some factors which contributed to feed such trends. On the one hand, the adoption of legal policies aimed at favoring urban land (Ley del suelo de 7/1997 de 14 de abril de medidas liberalizadoras en materia de suelo y de colegios profesionales). On the other hand, the adoption of the Euro in 2002, permitted money-laundering related to urban development. Also worth mentioning is the arrival of more than six million immigrants in a relatively short period of time, as well as the strong investment in communication infrastructures, by the public sector. New commercial centers proliferated around the urban areas. All this took place in a context where the average income kept increasing, which also favored home purchases. Finally, we could also to add the fact that banks gained entry into the building industry by providing easy credits for urban developers and final buyers. The building industry was acknowledged as the stabilizer of the economy, and small and big investors turned their attention to households, due to their capacity of generating capital gains [7-9]. All these factors worked together, until 2008.

The effects were visible in the different tiers of the urban hierarchy, mainly in the big and medium-sized cities, where there was a significant increase in population, and in urbanized land and housing. There is data available which illustrates what occurred during this decade, something that certain authors have rightly labelled as "the prodigious decade of Spanish urbanism" [8], although others have been more critical and have presented it as the "brick economy" or the "urbanizing tsunami" [9,10]. Between 2002 and 2008, the most intensive years, nearly 3.7 million homes were built, and in 2006, which was the greatest exponent of the urbanizing years in the model, almost seven hundred and fifty thousand households were constructed (number of homes according to work license, Ministerio de Fomento, 2017 [11]). Likewise, it was a period of strong demographic dynamism, in which the Spanish population increased by 4.3 million people, mainly as a consequence of international immigration (the population grew from 41.8 to 46.1 million people, according to the Spanish National Statistics Institute).

The effects of this process, on the territory, have been highly intense, as most of the urban expansion was made in the form of big developments of collective housing, or as single-family houses on the outskirts of well-connected areas. The data supplied by the Corine Land Cover, show that in Spain, on average, there was an increase from $6700 \mathrm{~km}^{2}$ to $10,170 \mathrm{~km}^{2}$ of developed areas, between 1987 and 2006 ( $3470 \mathrm{~km}^{2}$, equivalent to 34\%; the highest ever growth in Spanish history). In fact, the increase in housing was higher than the actual needs of the population, although this affirmation could be different in certain territories, especially in those where the dynamics have been affected by tourism related to second dwellings, mainly on the islands (Baleares and Canary Islands) and the Mediterranean coast (Andalucia, Murcia, the Valencian Community, and Catalonia).

From 2008, the effects of the high level of financialization of the economy and the debt of the governments, the administration, and households, triggered a structural crisis which dramatically affected the Spanish economic model. The bubble burst resulted in the collapse of the markets, the failure of financial institutions caused by the non-payment of debt, or by high risk (mainly savings banks), and provoked a sharp decline in real-estate and financial activity, as a side effect. Furthermore, in urban areas, regional, urban, and social issues were uncovered. There was a paralysis of the financial 
activities, capital gains, and transactions. The construction market decelerated significantly, so in 2013, the least active year during the crisis cycle, only 31,000 new houses were created ( $5 \%$ of the houses built in 2007). Meanwhile, the behavior of the population had also changed reflecting a drop, in housing sales since 2012. The average price of housing dropped by 30\%, between 2007, when the highest prices of built $\mathrm{m}^{2}$ were reached and 2014 that is, when the lowest prices appeared. Wages were lowered and unemployment indices increased (1.7 million in 2007 to 6.2 million in 2013). In addition to this, there were social effects derived from poverty (according to different criteria), which were very clear in the processes of eviction, as many of them were in the hands of financial entities [12]. The territorial and urban consequences have left many developed areas without buildings, and provided many examples of failed constructions. There has remained a considerable suplie of houses and vacant urban land.

As a result of these processes, different issues and social realities have emerged. The academic field has approached them in a new reflective scenario, where the analyses are contributing to help us understand the nature of conflicts and their resulting situations. Tis work, Readings of the Post-Crisis Spanish City: Between Social Inequity and Territorial Destruction is meant to contribute to such debates. We pay attention to different urban scales (big cities, metropolitan areas, towns, and urban areas) and space (inland Spanish towns, coastal cities, and main cities, such as Madrid, Barcelona, and Valencia). In terms of topics, other aspects related to morphological transformations are addressed, in order to present the negative effects caused by geographic dispersion and territorial overflow that have taken place in metropolitan areas and the environment, associated with daily mobility and sustainability. There is a clear need of revising the strategies linked to services and public infrastructure (water management not only in touristic areas, but in cultural spaces, sports areas, transports, hospitals, and communication centers, as well), in order to solve the growing territorial fragmentation in urban, industrial, commercial, and leisure areas. We present some issues that have taken place in the traditional historical or functional centers, which have happened to become affected by segregation, dispossession, vulnerability, gentrification, and social inequalities. The relation between the city and the nearby rural environments or the new sustainable responses, is also present. Another aspect that should be noted is governance, which is understood as the management of different political and administrative fragmented spaces that encompass the same territorial reality-issues of conurbation and how democratization of decision making affects communities, by incorporating citizen engagement is also analysed. These works were initially presented in the 14th Congress of Urban Geography from the Society of Spanish Geographers (XIV Congreso de Geografía Urbana de la Asociación de Geógrafos Españoles). The authors have performed a revision of the texts, in order to transform the initial ideas into twelve book chapters, which combine a scientific analysis with a profound critical view of a whole series of processes that played a crucial role in the interpretation of Spanish cities in the 21st century, as seen from a development point of view and an intra-urban characterization.

Not only did urban sprawl processes affect big Spanish cities, but also towns, where these processes have paradoxically been greater than in the nearby cities. This is a phenomenon which Luis A. Escudero, Irene Sánchez, and Francisco Cebrián (University of Castile-La Mancha) present in two chapters (Land Squandering in the Spanish Medium Sized Cities: The Case of Toledo; Urban Sprawl in Inner Medium-Sized Cities: The Behaviour in Some Spanish Cases Since the Beginning of the 21st Century), Toledo being the case study in one of them. In another chapter, a group of 23 different Spanish cities are presented, where the relation between population, urbanized surface, and built surface is analyzed. Their conclusions indicate that even though the dispersion dynamics have been bigger in the inserted medium-sized cities, with a polynuclear metropolitan area, the areas that are further away from the big cities tend to maintain trends that are closely associated with demand for growth. The consequences of this situation can be observed through disjointed and morphologically impersonal spaces, as well as the abundance of unfinished spaces and uninhabited urbanizations, whose future is quite uncertain.

In any case, authors like Arlinda García y Cristina López (University of Barcelona) (The Impact of Economic Crisis in Areas of Sprawl in Spanish Cities), who analyzed the case of Barcelona, consider that dispersed areas still retain their appeal for people in the life stages of the creation and expansion of 
households. They accept that, for this reason, an effective economic recovery and a renewed rise in the price of housing in denser cities, might contribute to an upturn in the popularity of the dispersed residential model, which nowadays could be considered to be in a "lethargic" phase, waiting for certain factors to concur and reactivate its expansion.

There is solid scientific evidence of the impact of urban sprawl on the growth of big cities, and medium-sized cities and towns, resulting in a web that Joan Checa y Oriol Nel-lo (Autonomous University of Barcelona) (Urban Intensities. The Urbanization of the Iberian Mediterranean Coast in the Light of Nighttime Satellite Images of the Earth) have studied through night-time light. They have analyzed urban development not only from the point of view of the physical occupation of land, but have also considered the changes in the intensity of the deployment of space. Through a complex procedure of image interpretation of satellite images of the Earth, they have proved how light intensity can serve as an indicator of efficiency, with regards to the use of territory and resources, the population distribution, and the production of goods and services; so the best lit areas do not always correspond to the areas with the highest populated areas, and the absence of urban brightness does not automatically indicate an absence of urban use.

Álvaro Morote (University of Valencia), Jorge Olcina, Antonio M. Rico, and María Hernández (University of Alicante) (Water Management in Urban Sprawl Typologies in the City of Alicante (Southern Spain): New Trends and Perception after the Economic Crisis?) introduced the impacts of territorial transformations which have occurred on the Spanish Mediterranean coast, due to the increase of urbanized and built lands, which have generated contradictions and internal conflicts that are linked to the overconsumption of resources (land, energy, water) and pollution (air, water, heat island effect, urban solid waste). Taking the city of Alicante as a reference, they are able to demonstrate how certain urban sectors that are characterized by low-density urban development, are not very sustainable, particularly, in terms of water management. They have successfully confirmed that water use per single family detached house amounted to $712 \mathrm{~L}$ per day, due to the high water demand, such as watering the garden or filling the swimming pool. These are alarming figures, more importantly so if we take the dynamics of the Mediterranean climate into account and how water scarcity might aggravate in the future.

In contrast to overbuilding, urban sprawl, and urban expansion, different initiatives emerge as a way of pursuing environmental sustainability in the city. This is the case of Eco-Neighborhood Projects in the city of Madrid, which are presented by Elia Canosa and Ángela García (Autonomous University of Madrid) (The Failure of Eco-Neighborhood Projects in the City of Madrid (Spain)). This is a project that could mean the arrival of innovative initiatives to the neighborhood of Vallecas (South Madrid), which might provide centralized heating and hot water for all buildings, as well as the installation of an underground solid waste collection system. With this project, the three basic dimensions of sustainability could be tackled - the environment, the society, and the economy. However, according to the authors, the result might not be as expected. The cause could be the existing gap between the projects and their achievements, between official statements and urban practices, and finally, between the wishes of politicians and technicians, and the aspirations of citizens. In this sense, the lack of the residents' participation, burdened the entire process, even the start-up of the built elements.

Roxana-Diana Ilisei and Julia Salom (University of Valencia) (Urban Projects and Residential Segregation: A Case Study of the Cabanyal Neighborhood in Valencia (Spain) study the residential mobility processes that are associated with the urban sprawl in the historical neighborhood of Cabanyal (Valencia). The authors identified the territorial pattern of the socio-demographic changes that have affected the neighborhood during the last decade. They linked such changes to the cycle of urban degradation that the neighborhood is familiar with, and also to the renovation plans. The authors present an exhaustive research backed by abundant graphic and cartographical material, where they proved that, due to the neoliberal policies in the Special Plan for Protection and Interior Reform (PEPRI), there was a progressive loss of the Spanish population and non-EU immigrants (who were mostly Colombians and Equadtorians, until that point) by other EU immigrants (mostly Romanians). To 
conclude, Ilisei and Salom claimed that the dynamics of the residential changes in Cabanyal, during the recent years, indicated that the processes of residential segregation, have created a strong social inertia and resistance towards urban revitalization policies implemented by the new municipal government.

Foreclosures and evictions were the main social impacts of the 2007 crisis, but are also a cause of a society based on social inequality. In recent years, many documents about evictions in Spain have been published. This can not only be explained by a rise in the number of evictions in the last decades, but can also be accounted for by the necessity of expanding the city beyond its physical territory as well, as a social product of a constant revision. As shown by Juan M. Parreño, Josefina Domínguez, Maite Armengol, Tanausú Pérez, and Jordi Boldú (University of Las Palmas de Gran Canaria) (Foreclosures and Evictions in Las Palmas de Gran Canaria during the Economic Crisis and Post-Crisis Period in Spain), evictions increased significantly during the crisis, but these have not ceased to show an upward tendency, thus, causing a complex situation. Dispossession and loss of use are two structural occurrences that are coherent with the capitalist model of secondary accumulation developed in the world, in the last 20 years. The authors focused on the study of the territorial impact and the trend of mortgage foreclosures and evictions in the urban space of Las Palmas de Gran Canaria, from 2009 to 2017, and it contributed to understanding the causes and delved into this debate with solid scientific evidence. Working with disaggregated data (street names and gate number) from judicial statistics, provides a highly detailed spatial dimension. The city that was studied was very interesting, due to the fact that it was located in the outermost European region, in an important tourist destination where the international property demand is quite high. Between 2009 and 2017, a total of 4138 case files aimed at the forcible deprivation of use and ownership, were executed in the judicial district for Las Palmas de Gran Canaria, 460 case files per year and 1.2 per thousand inhabitants. In conclusion, two main results must be emphasized. On the one hand, as proved by other researchers [12], the territorial distribution of the legal actions adopted was generally concentrated in the city's central spaces, nonetheless, the incidence of dispossession and rental-related evictions, overflowed these spaces, and also intensely affected the urban periphery. On the other hand, dispossession in Las Palmas was concentrated in the early years of the crisis, whereas the loss of use had affected the more recent period, when the incipient post-crisis was taking place.

Barcelona was the case study in the next two chapters, where there was a coincidence in the use of innovative methodology for the study of the indicators of social inequality in urban areas, such as vulnerability and social segregation. Antonio Palacios, Ana Mellado (Autonomous University of Madrid), and Yazmín León (University of Costa Rica) (Qualitative Methodologies for the Analysis of Intra-Urban Socio-Environmental Vulnerability in Barcelona (Spain): Case Studies) present an interesting work about the socio-environmental vulnerability in the municipality of Barcelona, thanks to the use of qualitative methodologies. Focused on the social approach to vulnerability, they showed how socio-spatial structures and processes are indeed dynamic and might determine the daily lives of the disadvantaged people and groups. Thus, the objective was to show that qualitative methodologies can play a major part in the studies on urban socio-environmental vulnerability, when detecting deficiencies or non-quantifiable social and urban problems. The authors introduced a synthetic indicator of the relative socio-spatial vulnerability. Although this was calculated for all neighborhoods in Barcelona, the chapter was centered, as a case study, in the most vulnerable ones-Trinitat Nova, El Raval, La Marina del Prat Vermell, and La Barceloneta. They worked with seventeen variables related to education, age, and demographic mortality indicators; income and professional status, immigration status, and size of household. On the one hand, at the neighborhood level, the research crystallized in a synthetic index of relative socio-spatial vulnerability (ISVuSAR), which was represented by a map. An interesting table with qualitative indicators was presented for the four neighborhoods. The results revealed the multidimensionality of vulnerability in the neighborhoods analyzed, as well as the validity of qualitative methodology, to detect and support public policies that were destined to reducing intra-urban inequalities. 
Additionally, Aina Gomà and Joel Muñoz (Autonomous University of Barcelona) (Segregated in the City, Separated in the School. The Reproduction of Social Inequality through the School System) showed a study on urban sprawl, from the analysis of the education level of the population, an education which could replicate and spread social inequality in the city. Gomà and Muñoz contributed to this debate by producing a combined analysis of three variables-knowledge of the dynamics of urban segregation; educational levels achieved by the population aged between 15 and 34; and enrolment strategies and scholar performance, according to the place of residence. The last section was especially interesting, as it associates the socio-economic variables, the complexity of the schools' situation, and the academic results of the students. Albeit the information was presented with an introductory section about residential segregation and school segregation in Catalonia, the scale of the study was intra-urban-neighborhoods and school districts in Barcelona. To conclude, the authors affirmed that school segregation, as well as residential segregation, are directly intertwined and, therefore, education affects in the spread of inequality. On the one hand, the residential origin is of key importance in the professional career and expectations of the young population. On the other, spatial differences in the schools' conditions, act as enhancer elements for school segregation, due to, above all, the stigmatization of schools in the vulnerable neighborhoods, and the enrolment procedure.

The new companies of the so-called sharing economy were very important urban factors, for the transformation of the current cities, especially those that were related to tourism and gentrification. As a consequence, there is an important opportunity for research in urban studies. Luis del Romero (University of Valencia) (Touristification, Sharing Economies and the New Geography of Urban Conflicts) addressed this issue mainly from the point of view of tourism, in the third most populated city in Spain, Valencia. The new types of holiday rentals dominated by online marketplaces (such as Airbnb), Uber, and Cabify, which formed the center of the analyses. The most notable novelty in this chapter could be the relation between the outbreak of social conflicts in an urban area, which was measured by el Romero, from the location in the city map, with four factors in two different stages (real-estate bubble and crisis) - family evictions for tourist apartments, protests against touristification, protests against noise and public space privatization, and taxi driver protests. According to del Romero, the conflicts could be divided into three categories-land-use conflicts, land revenue conflicts, and mobility conflicts, which, like the studied sharing economy companies they face, have adopted a new organization scheme and renewed fight. Social networks are not only promoting digital platforms but also social resistances.

Another chapter is centered in the study of urban processes that take place in regions and beyond. In "The Clandestine Transition towards an Unsustainable Urban Model in Extremadura, Spain", Víctor Jiménez and José A. Campesino (University of Extremadura) (The Clandestine Transition towards an Unsustainable Urban Model in Extremadura, Spain) showed the unsustainability of the urban model in Extremadura, an autonomous community characterized by its weak urban system and the lowest $(49.07 \%)$ Average Urbanization Rate (AUR) in Spain. Nevertheless, Extremadura has seen an important development of rural areas, near cities and towns, mainly from a residential growth outside the limits of the urban and developable land. This has been an intense process in recent years which, according to the authors, is eminently clandestine. The methodologies and analyses from urban planning are predominant and they could be extrapolated to other territories. Among other results, the number and density of houses in the Undevelopable Land (UL) in the municipalities, are mapped. The authors detected almost 40,000 houses on the UL of Extremadura, with a very unbalanced distribution in the quantitative level but very distributed in spatial terms. Only two municipalities of the 388 that comprise Extremadura, are free of housing on the UL. As a conclusion, we highlighted, on one hand, that the atypical 'rururban' expansion is the main urban and territorial problem of the region. On the other hand, it is clear that Extremadura needs a new territorial scheme that conditions urban regulation. Extremadura must face the creation and application of a Regional Plan for Management and Control of Rurban Development. 
As a result of this revision set, we presented a reality marked by the end of unregulated expansive growth, the re-involvement of administrations in the process of planning and management of cities, the change in the territorial priorities of towns and cities, which have shifted their focus from metropolitan areas to more central neighborhoods; and the concern for those communities that were greatly affected by the crisis, which are still very present. It remains to be seen how the administrations will react to certain challenges, such as the overexploitation of lands, the energy transition, the need for services, the governance or the democratization of the decision-making process, among others.

Funding: This research has been funded by three research projects (Ministry of Science, Innovation and Universities/ FEDER): CSO2015-63970-R; CSO2016-75236-C2-1-R; CSO2015-68738-P.

Conflicts of Interest: The authors declare no conflict of interest.

\section{References}

1. Uhaldeborde, J.M. Las ciudades europeas: Nuevos paradigmas, nuevas estrategias. Pap. Econ. Española 2017, 153, 2-22.

2. Harvey, D. A Brief History of Neoliberalism; Oxford University Press: New York, NY, USA, 2005; p. 247.

3. Lois, R.C.; Piñeira, M.J.; Vives, S. El proceso urbanizador en España (1990-2014): Una interpretación desde la Geografía y la teoría de los circuitos del capital. Rev. Scr. Nova 2016, 20, 539.

4. Herce, M. El Negocio del Territorio. Evolución y Perspectivas de la Ciudad Moderna; Alianza: Madrid, Spain, 2013.

5. Valenzuela, M. Tendencias y desafíos de la planificación urbana y del gobierno del territorio. La perspectiva de los geógrafos españoles (2005-15). In Crisis, globalization and social and regional imbalances in Spain, Spanish Contribution to 33rd IGC Beijing; Asociación de Geógrafos Españoles: Madrid, Spain, 2016; pp. 211-229.

6. Baraona, M.; Herra, E. Danzando en la Bruma Junto al Abismo. Las Cuatro Crisis y el Futuro de la Humanidad; Lom Ediciones: Santiago, Chile, 2018.

7. Romero, J. Construcción residencial y gobierno del territorio en España. De la burbuja especulativa a la recesión. Causas y consecuencias. Rev. Cuad. Geogr. 2010, 47, 17-46.

8. Burriel, E. La Década Prodigiosa del Urbanismo Español (1997-2006); Scripta Nova, XII, 270 (64); Universidad de Barcelona: Barcelona, Spain, 2008.

9. Gaja, F. El "Tsunami Urbanizador" en el Litoral Mediterráneo. El Ciclo de Hiperproducción Inmobiliaria 1996-2006; $X$ Coloquio Internacional de Geocrítica. Diez Años de Cambio en el Mundo, en la Geografía y en las Ciencias Sociales, 1999-2008; Universidad de Barcelona: Barcelona, Spain, 2008.

10. Naredo, J.M. Un Episodio Relevante: La Burbuja Especulativa y la Crisis Inmobiliaria en Perspectiva. Cuad. Investig. Urbanística 2015, 100, 77-82. [CrossRef]

11. De Fomento, M. Observatorio de la Vivienda y Suelo, Boletín Anual 2017; Ministerio de Fomento. Gobierno de España: Madrid, Spain, 2017.

12. Vives, S.; Rullan, O.; González, J.M. Understanding Geographies of Home Dispossession through the Crisis: Evictions Palma Style; Icaria: Barcelona, Spain, 2018.

(C) 2019 by the authors. Licensee MDPI, Basel, Switzerland. This article is an open access article distributed under the terms and conditions of the Creative Commons Attribution (CC BY) license (http://creativecommons.org/licenses/by/4.0/). 